\title{
Based on the MIDAS GEN frame structure joints is just domain of values elastic-plastic static analysis
}

\author{
L. H. Yang ${ }^{1, a}$, F. MA ${ }^{1, b}$, J.Z. HOU $^{1, c}$ \\ ${ }^{1}$ Department of Civil Engineering, Taiyuan University of Technology \\ 79, Yingzexi Street, Taiyuan, 030024, China \\ ayanglinhai1@163.com, bs991400218@sina.com , choujinzhen1314@163.com
}

Keywords: strong earthquake, frame structure and plasticity analysis, plastic hinge, just domain, the seismic performance

\begin{abstract}
In this paper, the finite element analysis software MIDAS GEN structure, take give frame structure joints place just threshold method, the frame structures in the action of the rarely met earthquake elasto-plastic static analysis. Through comparing the different just domain length (not just domain, standard calculation just domain, the whole just domain) value of the structure under cycle, displacement, performance point, layer, layer between shear displacement between Angle and so on, is put forward based on the theory of plastic hinge under strong overall performance evaluation system structure. The results of the study show that: give frame structure joints of different just threshold, it will directly affect the structure of internal force and deformation of the structure seismic performance also has greater effect.
\end{abstract}

\section{The Preface}

In the practical calculation, the framework structure mechanics model according to the form of beam-column usually heart line simplified to a one dimension line unit, and when components section size relative its span is bigger, can form in the intersection beam-column relative rigid node area, and call it just domain. Just domain means that no quality, its own not only stiffness deformation, but can happen and the displacement of the rigid body displacement must be attached to the component is a idealized component. In practical projects, when considering just domain, the inevitable to structure of the internal force and deformation produce certain effect, and just domain length different values, will affect the structure of the seismic performance is good. Concrete structures of tall building technology procedures (JGJ3-2010) the first article 5.3.4 given clear just domain calculation formula of length. This paper consider beam-column joints place just domain length to the actual engineering as an example, the application of MIDAS software the elastic-plastic static analysis of frame construction under the effects of earthquake damage mechanism research, and through the change of joints place just domain length, discuss in Abraham under severe earthquake, Beam-column just domain length selection on concrete frame structure failure mechanism of influence.

\section{Engineering example}

A building project, a total of five layer, layer are $3600 \mathrm{~mm}$, frame beams cross section are 300 x700 (mm), the second beam section are 250 x500 (mm), concrete strength grade are C30, Beam-column advocate muscle HRB400 reinforced all use level, seismic fortification intensity of 7 degrees $(0.10 \mathrm{~g})$, the seismic grade for level 3 , the category of III, design for the second group earthquake group. Figure 1 and figure 2 for the plan of the office building, respectively with section. 


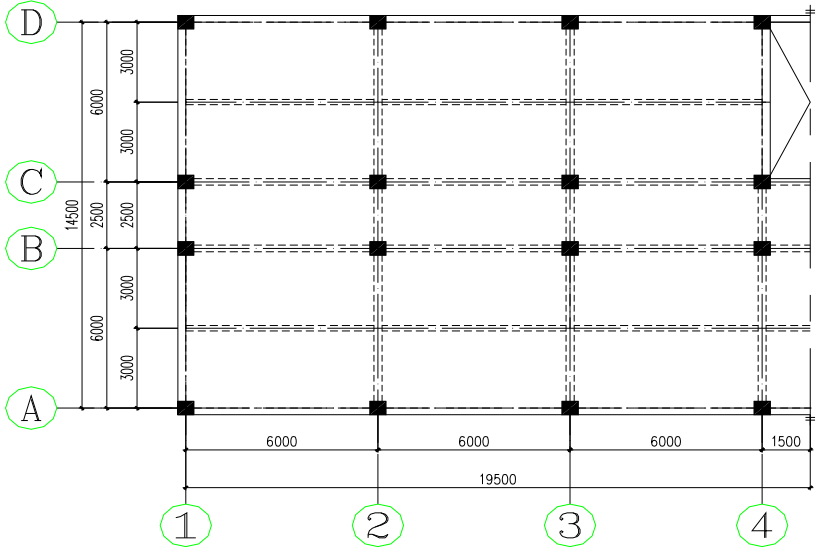

Figure 1

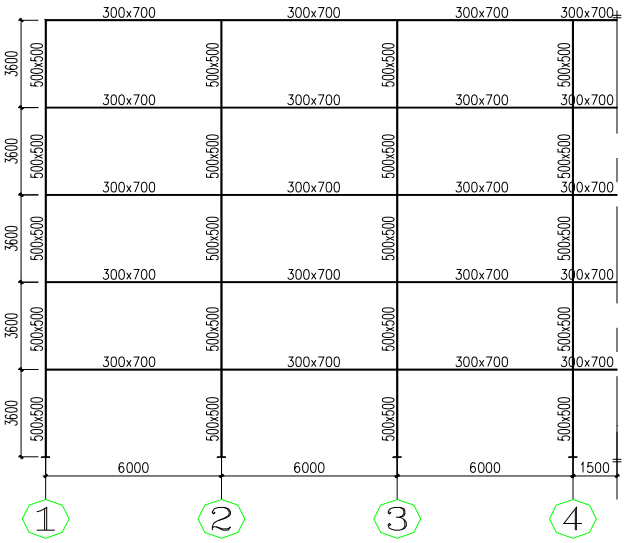

Figure 2

\section{Calculation and Analysis}

In this paper, the frame beam-column joints were considered in three different sets of just threshold, respectively is: (1) according to technical specification for concrete structures of tall buildings (JGJ3-2010) the first article 5.3.4 calculation of just threshold (2) all joints is considered just domain (3) in the joints don't consider just domain

\section{Structure elastic analysis}

The structures elastic analysis, comparative under earthquake effect to the parameters of the X, $\mathrm{Y}$, see the table below:

\begin{tabular}{|c|c|c|c|c|c|c|c|c|c|c|c|c|}
\hline \multirow[b]{2}{*}{$\begin{array}{l}\text { categor } \\
\text { ies }\end{array}$} & \multicolumn{6}{|c|}{$\mathrm{X}$ to the earthquake effect } & \multicolumn{6}{|c|}{ Y to the earthquake effect } \\
\hline & \multicolumn{2}{|c|}{$\begin{array}{l}\text { No just } \\
\text { domain }\end{array}$} & \multicolumn{2}{|c|}{$\begin{array}{l}\text { Standard value } \\
\text { just domain }\end{array}$} & \multicolumn{2}{|c|}{$\begin{array}{l}\text { All just } \\
\text { domain }\end{array}$} & \multicolumn{2}{|c|}{$\begin{array}{l}\text { No just } \\
\text { domain }\end{array}$} & \multicolumn{2}{|c|}{$\begin{array}{l}\text { Standard value } \\
\text { just domain }\end{array}$} & \multicolumn{2}{|c|}{ All just domain } \\
\hline \multirow{3}{*}{$\begin{array}{l}\text { period } \\
\text { (s) }\end{array}$} & T1 & 0.9877 & $\mathrm{~T} 1$ & 0.8992 & $\mathrm{~T} 1$ & 0.8098 & $\mathrm{~T} 1$ & 0.9877 & $\mathrm{~T} 1$ & 0.8992 & $\mathrm{~T} 1$ & 0.8098 \\
\hline & $\mathrm{T} 2$ & 0.9588 & $\mathrm{~T} 2$ & & $\mathrm{~T} 2$ & 0.7 & $\mathrm{~T} 2$ & 0.9 & $\mathrm{~T}_{2}^{2}$ & & $\mathrm{~T} 2$ & \\
\hline & T3 & 0.9106 & T3 & & T3 & 0.7 & T3 & 0.9 & & & T3 & \\
\hline \multirow{5}{*}{$\begin{array}{c}\text { Displa } \\
\text { ce- } \\
\text { ment } \\
\text { (rad) }\end{array}$} & F1 & $1 / s$ & F1 & & $\mathrm{F}$ & $1 / \mathrm{s}$ & 71 & 13 & F1 & & F1 & $1 / 994$ \\
\hline & $\mathrm{F} 2$ & $1 / 637$ & F2 & 713 & 1 & $1 / \varepsilon$ & $\mathrm{F} 2$ & 8 & $\mathrm{~F}_{2}$ & & $\mathrm{~F} 2$ & $1 / 811$ \\
\hline & F3 & $1 / 722$ & F3 & $1 / 815$ & $F_{3}$ & $1 / 9$ & F3 & 697 & F3 & 2 & $F_{3}^{3}$ & $1 / 912$ \\
\hline & F4 & $1 / 988$ & $\mathrm{~F} 4$ & 7 & $\mathrm{~F}$ & 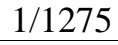 & F4 & $1 / 925$ & F4 & 44 & F4 & 1/1188 \\
\hline & F5 & $1 / 1784$ & F5 & $1 / 2$ & F5 & $1 / 2281$ & F5 & $1 / 1575$ & $\mathrm{FS}$ & $1 / 1744$ & F5 & $1 / 1940$ \\
\hline \multirow{5}{*}{$\begin{array}{l}\text { shear } \\
(\mathrm{kN})\end{array}$} & F1 & 5137 & F1 & 5554 & F1 & 6050 & F1 & 4995 & F1 & 5416 & F1 & 5930 \\
\hline & $\mathrm{F} 2$ & 4759 & $\mathrm{~F} 2$ & 5133 & $\mathrm{~F} 2$ & 5576 & F2 & 4630 & $\mathrm{~F} 2$ & 5009 & $\mathrm{~F} 2$ & 5470 \\
\hline & F3 & 3976 & F3 & 4276 & F3 & 4629 & F3 & 3879 & F3 & 4187 & F3 & 4560 \\
\hline & $\mathrm{F} 4$ & 2849 & $\mathrm{~F} 4$ & 3047 & F4 & 3280 & F4 & 2797 & $\mathrm{~F} 4$ & 3004 & $\mathrm{~F} 4$ & 3257 \\
\hline & F5 & 1401 & F5 & 1483 & F5 & 1578 & F5 & 1391 & F5 & 1478 & F5 & 36 \\
\hline
\end{tabular}

Note: T1, T2 and T3 said the first three respectively structure modes, F1, F2, F3, F4 and F5 says floor 1, 2, 3, 4, and 5 layers.

Analysis of the above data can be concluded that the three just thresholds next: no just domain in when X, Y to natural vibration period, displacement were the biggest, floor horizontal seismic shear minimum, show that the minimum structure stiffness. Just when the fields on natural vibration period, displacement are minimal, floor horizontal seismic shear is the largest, show that structure stiffness is the largest. Standard value just domain cycle, displacement, stiffness size is located in between. Each floor will meet the displacement of the seismic design of building codes (GB50011-2010) 5.5.1 function of elastic layers displacement Angle 1/550 of the limit.

\section{Structure elasto-plastic analysis}

In this article, the MIDAS/Gen set the girder ends of the length of just domain method, the elastoplastic static whole structure analysis. In the X, Y respectively to exert horizontal earthquake effect, lateral force using modal loading PUSHOVER analysis way, the contrast in the elastic-plastic stage structure, three just domain of various performance parameters under length.

\section{Performance point}


From the analysis of the software to see, in all the conditions are capacity spectrum curve can and demand spectrum curve intersection get performance point that structure with good seismic performance, and the ability of the spectrum curve relatively smooth, in under the shock of elastic or a few basic for the hinge, and under the conditions of the earthquake has entered into the plastic. The performance of the point the parameters see table 1 :

\begin{tabular}{|c|c|c|c|c|c|}
\hline \multirow{3}{*}{$\begin{array}{c}\text { X to } \\
\text { Performance } \\
\text { point }\end{array}$} & Just domain length & Sa & Sd & Vb (KN) & Un $(\mathrm{m})$ \\
\cline { 2 - 5 } & No just domain & 0.1615 & 0.06386 & 12050 & 0.0875 \\
\cline { 2 - 5 } & Standard value just domain & 0.173 & 0.0587 & 12950 & 0.08 \\
\hline \multirow{2}{*}{$\begin{array}{c}\text { Performance } \\
\text { point }\end{array}$} & All just domain & 0.1836 & 0.05062 & 13800 & 0.0688 \\
\cline { 2 - 5 } & No just domain & 0.1498 & 0.06406 & 11370 & 0.086 \\
\cline { 2 - 5 } & Standard value just domain & 0.1614 & 0.06015 & 12240 & 0.08 \\
\hline
\end{tabular}

From the above analysis, we can see that take $\mathrm{X}$ to point the vertices of the largest performance displacement $\mathrm{UN}=0.0875 \mathrm{~m}<1 / 50 \times 18=0.36 \mathrm{~m}(1 / 50$ is seismic code provisions of elastic-plastic layer displacement between Angle limitation), therefore, to meet the vertex displacement $\mathrm{X}$ plastic limit requirements. Point to take Y performance the biggest UN $=0.086 \mathrm{~m}<1 / 50 \times 18=0.36 \mathrm{~m}$ (1/50 is seismic code provisions of elastic-plastic layer displacement between Angle limitation), so, $\mathrm{Y}$ to also meet the vertex displacement plastic limit requirements. And in the performance of the state to point $\mathrm{X}$ and $\mathrm{Y}$ to the maximum displacement between floors Angle see table 1:

\begin{tabular}{|c|c|c|c|}
\hline $\begin{array}{c}\text { Loading } \\
\text { method }\end{array}$ & $\begin{array}{c}\text { Just domain } \\
\text { numerical }\end{array}$ & $\begin{array}{c}\text { PUSH-DX } \\
\text { (X to the maximum displacement } \\
\text { between floors Angle) }\end{array}$ & $\begin{array}{c}\text { PUSH-DY } \\
\text { (Y to the maximum displacement } \\
\text { between floors Angle) }\end{array}$ \\
\hline \multirow{3}{*}{ modal } & No just domain & $1 / 117$ & $1 / 138$ \\
\cline { 2 - 4 } & Standard value just domain & $1 / 122$ & $1 / 141$ \\
\cline { 2 - 4 } & All just domain & $1 / 132$ & $1 / 145$ \\
\hline
\end{tabular}

From the above analysis view of structure in the earthquake, layer displacement Angle between will meet the standard seismatic design architecture (GB50011-2010) table 5.5.5 requirements of the elastic-plastic layer displacement Angle between 1/50 of the limits that structure has better seismic performance.

\section{Plastic hinge}

In the analysis, the MIDAS/Gen finite element program is through the plastic hinge to realize the structure of the material nonlinearity, the plastic hinge on pole of elastic-plastic model to represent component performance, this paper applied "yield force and the yield displacement" normalization method, define beam hinge (moment, shear hinge), column hinge (PMM hinge) "generalized force-generalized displacement" curve. Through the PUSHOVER analysis, it is concluded that the proportion of plastic hinge, see table 1:

\begin{tabular}{|c|c|c|c|c|c|c|c|c|c|c|}
\hline \multirow{3}{*}{$\begin{array}{l}\text { Just domain } \\
\text { length }\end{array}$} & \multicolumn{10}{|c|}{ The proportion of plastic hinge (\%) } \\
\hline & \multicolumn{5}{|c|}{ PUSH-DX（PP） } & \multicolumn{5}{|c|}{ PUSH-DY（PP） } \\
\hline & $\mathrm{B}-\mathrm{I0}$ & I0-LS & $\begin{array}{l}\text { LS-C } \\
P\end{array}$ & CP-C,D & C,D-E & $\mathrm{B}-\mathrm{I0}$ & I0-LS & $\begin{array}{l}\text { LS-C } \\
P\end{array}$ & CP-C,D & $\begin{array}{l}\text { C,D- } \\
\text { E }\end{array}$ \\
\hline No just domain & $4.9 \%$ & - & - & - & - & $4.2 \%$ & $1.9 \%$ & - & - & - \\
\hline $\begin{array}{l}\text { Standard value } \\
\text { just domain }\end{array}$ & $4.4 \%$ & $1.1 \%$ & - & - & - & $4.6 \%$ & $2.2 \%$ & - & - & - \\
\hline All just domain & $4.6 \%$ & $1.4 \%$ & - & - & - & $3.7 \%$ & $1.8 \%$ & - & - & - \\
\hline
\end{tabular}

Note: said did not appear plastic hinge, the data in the table is the presence of the rod of the plastic hinge with a total stem a percentage of the structure

From the graph can see, three cases, structure component performance in most of the hinge IO LS stage, the results show that the structure component has entered the yield at stage, and the structure of components for moderate damage, there is a clear cracks in the component. Among them, not just domain cases, structure in the $\mathrm{X}$ direction component performance hinge in $\mathrm{B} \sim \mathrm{IO}$ stage, show that this time just entered the plastic components, plastic degree is shallow. Standard value just domain, the $\mathrm{Y}$ direction plastic hinge for the biggest proportion, all just domain, $\mathrm{X}$ direction plastic hinge for the biggest proportion. 


\section{Layer shear-the displacement curve}

The frame structure of the first layer for shear layer-the displacement curve, 2 layer displacement curve and shear-first floor close, three layer from the whole layer shear displacement curve-to see, is about to enter elastic-plastic stage, and four, five layer is in elastic stage. Due to the limited length, the only one on the list of shear-the displacement curve.
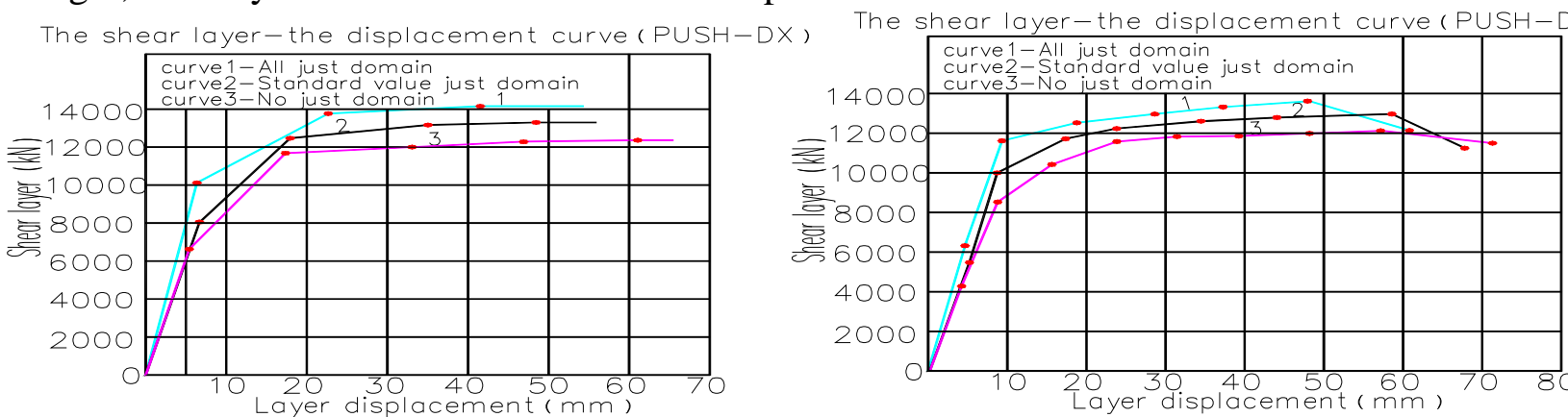

From above to see, $\mathrm{X}$ direction structure in the first place into the elastic-plastic stage turning point, along with the pushover increasing, the structure in the second turning point place into the plastic deformation stage, then the shear layer are less growth, and displacement between floors but change is larger, but were not beyond standard allowed scope. From the graph still can see, interlayer shear displacement curve is increasing basic linear, curve set displacement in range does not appear for fall, show that in the resistance there is great room for collapsed ability.

$\mathrm{Y}$ direction in the first place into the structure turning point elastic-plastic stage, along with the pushover increasing, the structure in the second turning point in the inelastic phase, the shear layer are less growth, and displacement between floors but change is larger, but were not beyond standard allowed scope. At the same time, in the curve ends, appear significantly reduced section, from the overall structure of the deformation to see, in Beam-column Joints all just domain cases, displacement between floors to $48 \mathrm{~mm}$, on the first floor column in the deep plastic hinge, show that this time structure has lost bearing capacity. According to the standard Beam-column Joints structure in the field just value, the displacement between floors to $54 \mathrm{~mm}$, on the first floor column in the deep plastic hinge, structure in Beam-column Joints no just domain cases, displacement between floors to $58 \mathrm{~mm}$, on the first floor column in the deep plastic hinge. Through the above analysis shows that structural damage, all the just domain of the structure under minimum displacement between the layers, its ductility is the worst.

To sum up, in under the action of the rarely met earthquake, when Beam-column Joints consider all just domain, shear layer than the other two kinds of circumstances is the largest, explain the structure of pushover, the domain of the structure under the earthquake had the greatest influence, also more serious damage. When Beam-column Joints don't consider just domain, shear layer than other two kinds of circumstances minimum, when the same beam-column point specification requirements according to consider just threshold, the shear layer in between.

\section{Epilogue}

In this paper the MIDAS finite element analysis, in the framework structure joints of the place just domain length (not just domain, standard value just domain, all just domain) problems in study, studies show that node length of different domain to just the level of structure seismic shear force and displacement, cycle all affect, and to structure the elastoplastic static analysis, beam-column joints area just domain length between layers of different shear effect is particularly significant, and with the length of the field just increase, and between shear layer in increase gradually, this means that structure of the earthquake action in also gradually increase, so the structure in the earthquake damage degree gradually was also intensified. The analysis and calculation of the standard in China are just domain length method, the structure in the earthquake damage degree between the just domain and no just between domains, and considering the size of their own section beam-column just domain the influence of length, is a reasonable setting method, meanwhile, frame beam-column 
joints area due consideration of just domain can effectively prevent the damage degree of quake on the structure.

\section{References}

[1] GB50011-2010 (2010 edition) building seismic design specification [S]. (China architecture \&building press, Beijing, 2010)

[2] High-rise building reinforced concrete structure design concept, hubei party China (mechanical industry press, Beijing, 2007)

[3] MIDAS/Gen application example tutorial and troubleshooting C.X Wang editor (China architecture \&building press, Beijing, 2010)

[4] Complex high-rise building structure seismic theory and application for the X.L lv (science press, Beijing, 2007)

[5] Node just domain of reinforced concrete frame structure seismic influence on the performance of the Z.F Zhang (hefei university journal 2010) 